\title{
Tempo e intencionalidade temporal no Wittgenstein do período intermediário
}

\author{
Denis Perrin \\ Université de Grenoble II \\ perrin.denis@neuf.fr
}

resumo Este artigo enfoca a questão da temporalidade no período intermediário de Wittgenstein. Primeiro, ele estabelece a evolução do tratamento que o filósofo dispensa à idéia "fenomenológica", de origem empirista, de um presente da consciência incessantemente fluente: de início simplesmente adotada (em 1929) como uma descrição da experiência imediata, essa idéia é, em seguida, criticada em 1930-32 como a expressão de uma das tentações mais características do espírito filosófico. Depois, o artigo examina, num caso particular (o da lembrança), o modo pelo qual Wittgenstein lida com os efeitos desse mito na reflexão filosófica. Endereçada sobretudo à concepção russelliana de 1921 da intencionalidade mnemônica, a crítica wittgensteiniana consiste em trazer à luz as confusões que levam a crer que a lembrança só pode manter uma relação externa com seu objeto. Ao restabelecer assim o papel das relações internas, Wittgenstein pretende romper o feitiço do mito do presente sobre a filosofia da memória.

palavras-chave tempo; Wittgenstein; memória; fenomenologia; relação interna; intencionalidade

Tomarei como estabelecido, nesta exposição, que o que foi chamado de «fenomenologia» por Wittgenstein em 1929 é ao mesmo tempo um simples episódio - e, a bem dizer, um episódio relativamente breve - e um momento central do percurso filosófico de Wittgenstein. Simples episódio, pois ele só se estende ao longo de poucos meses do ano de 1929; além disso, ele não constitui uma concepção completamente determinada nem um conjunto de afirmações às quais Wittgenstein teria plenamente aderi-

Recebido em 25 de maio de 2008. Aceito em 04 de outubro de 2008.

Tradução: Bento Prado Neto.

doispontos, Curitiba, São Carlos, vol. 6, n. 1, p.97-124, outubro, 2009 


\section{8}

do. Trata-se antes de uma tentação muito forte que veio a dominá-lo. Pela importância que a fenomenologia tinha a seus olhos, ele quase nunca deixou de examinar o modo pelo qual ela estende suas ramificações no pensamento filosófico: assim, muitas das questões sobre as quais Wittgenstein refletiu até 1951 provêm dessa concepção, e inúmeras das imagens filosóficas que o obsedaram aparecem pela primeira vez no contexto da fenomenologia de 1929. Dentre essas imagens, aquelas que dizem respeito ao tempo receberam uma atenção especial de sua parte. Como se sabe, a fenomenologia é pensada como uma análise da percepção, e especialmente do espaço visual. Mas dificilmente se pode refletir a respeito deste último sem levar em conta o vínculo que o une à temporalidade. Wittgenstein vem afirmá-lo explicitamente já no mês de fevereiro de 1929:

Es scheint mir eine eigentümliche Eigenschaft der räumlichen

Aussagen, dass man scheinbar den Raum ohne irgendeine Anspielung auf die Zeit nicht beschreiben kann. Ich kann z. B. sagen: „Ich sehe jetzt einen roten Kreis auf blauem Grund“. Das ist ein Satz. Aber ich kann nicht sagen ,ein roter Kreis ist auf blauem Grund“.

Es ist eigentlich von vornherein wahrscheinlich dass die Zeit in die Betrachtung des Gesichtsraumes nicht nachträglich als ein Anhängsel eintreten kann. ${ }^{1}$

Também poderíamos dizer que a temporalidade pertence à forma lógica dos fenômenos ou, de modo mais geral, que nessa época Wittgenstein toma consciência da gramaticalidade do tempo. O tempo, aliás, será problematizado em seu pensamento até as Investigações filosóficas e as Observações sobre a filosofia da psicologia ${ }^{2}$. Em particular, Wittgenstein irá defrontar-se, a partir de 1929, com aquilo que chamarei de «mito do presente» e com as conseqüências que ele acarreta no campo da filosofia da psicologia. Tais são as razões pelas quais irei consagrar esta exposição à questão da intencionalidade da memória, assim como ao modo pelo qual Wittgenstein, ao longo do período intermediário, procura libertar essa questão do mito que acabo de evocar.

\section{0 tempo: do presente fluente ao mito do presente}




\section{Uma leitura e sua crítica}

A fim de compreender o que Wittgenstein escreve acerca da intencionalidade temporal ao longo do período intermediário, convém começar por examinar as análises que ele dedica à questão do tempo. Irei encetar esse trabalho levantando algumas objeções contra um determinado modo de ler Wittgenstein, modo de ler que é ilustrado pelo livro de Byong-Chul Park (PARK, 1998), e que é bem próximo do de Hintikka (HINTIKKA, 1996).

Duas teses (entre outras) são sustentadas por Park, das quais discordo. Em primeiro lugar, Park afirma, acerca da concepção wittgensteiniana dos fenômenos em 1929, antes daquilo que Park chama «o desvio na direção do paradigma da linguagem fisicalista» : «No fundo, o mundo dos fenômenos é atemporal» (p. 84). Park extrai essa conclusão da seção 48 das Philosophische Bemerkungen, onde Wittgenstein pergunta: «Wenn die Welt der Data zeitlos ist, wie kann man dann überhaupt über sie reden?». Parece-me que a conclusão de Park repousa unicamente sobre a consideração do texto das Philosophische Bemerkungen e desconsidera largamente os manuscritos, nos quais, no entanto, Wittgenstein é bem mais explícito: no manuscrito 105 (p. 86/88), com efeito, Wittgenstein afirma que «o primeiro sistema é temporalmente ordenado»; há, portanto, uma temporalidade fenomenológica. E, conseqüentemente, a questão que se põe não é a de saber se há tal temporalidade, mas a de saber o que ela é e quais relações ela mantém com o tempo físico.

Em segundo lugar, segundo Park, enquanto Wittgenstein opera sua transição da linguagem fenomenológica para a linguagem fisicalista no final de 1929, «o que está em jogo não é a existência ou a não-existência dos objetos, nem o estatuto metafisico dos objetos»; e Park acrescenta: «Ele chegou a pensar que o mundo da experiência imediata, que muda a cada instante, poderia ser descrito por meio de uma linguagem ideal que refletiria a fenomeno-lógica. Wittgenstein chega à conclusão, por volta de 1929, de que sua posição anterior é impossível» (ver PARK, 1998, p. 85 e 84-5, respectivamente). Quanto a mim, penso que Wittgenstein na verdade desemboca em duas conclusões sucessivas e bastante diferentes. De um lado, no final do ano de 1929 e no início de 1930, ele acaba por considerar que não há algo como um "presente fluente» dos fenômenos que a linguagem fenomenológica teria por tarefa descrever - e, isso, muito embo- 
ra ele continue a sustentar que há algo que não conseguimos descrever. De outro, a partir de 1931-1932, Wittgenstein considera que não há sequer algo como a essência lógica do mundo que nossa linguagem fracassaria em apreender - e isso quer dizer que, a partir de então, nem a imagem do presente e nem sequer a motivação que leva a adotá-la têm valor algum. Cabe, portanto, dizer que ocorre uma mudança com relação ao estatuto metafísico que os objetos possuíam no final de 1929, uma vez que doravante Wittgenstein rejeita a imagem do mundo fenomenológico que ele antes adotara, e uma vez que, depois disso, ele acaba por reconhecer que não há sequer algo que a linguagem fenomenológica conseguiria ou não conseguiria descrever: a «impossibilidade» da descrição deve portanto ser finalmente concebida como uma impossibilidade lógica radical, e não (como o sugere Park) como uma simples impossibilidade factual. De um ponto de vista filosófico mais amplo, essa crítica wittgensteiniana radical atinge no coração inúmeras concepções filosóficas consagradas a trazer uma solução à cruz secular da consciência do tempo - tal é, sem dúvida, um aspecto bastante interessante dessa crítica.

Como o leitor pode ter pressentido, o que acabo de dizer leva imediatamente à recusa de ver no Tractatus algo como uma fenomenologia (mas deixarei esse ponto de lado) e à tese de que o pensamento de Wittgenstein é objeto de uma forte evolução ao longo de todo o período intermediário - o que procurarei mostrar de modo mais detalhado agora.

\section{O mobilismo heracliteano e o solipsismo instantaneísta}

Uma boa maneira de justificar as observações precedentes consiste em examinar duas formulações filosóficas, estreitamente vinculadas uma à outra, que exprimem ambas o tempo fenomenológico tal como Wittgenstein o concebia ao longo do ano de 1929: trata-se do heracliteanismo (expresso pelo dictum: Alles fliesst) e do solipsismo do instante presente (ou) do solipsismo instantaneísta (expresso pelo dictum: Nur die gegenwärtige Erfahrung ist real).

1. Parece-me de extrema importância ressaltar o parentesco que esses dois traços do tempo fenomenológico podiam apresentar, para Wittgenstein, com a concepção de W. James sobre o tempo da consciência, tal como formulada no capítulo 15 do seu Principles of Psychology: 
The duration thus steadily perceived is hardly more than the "specious present" (...). Its content is in a constant flux, events dawning into its forward end as fast as they fade out of its rearward one, and each of them changing its time-coefficient from "not yet", or "not quite yet", to "just gone", or "gone", as it passes by. Meanwhile, the specious present, the intuited duration, stands permanent, like the rainbow on the waterfall, with its own quality unchanged by the events that stream through it (JAMES 1983, p. 593).

Esse texto ilumina dois traços essenciais do presente fenomenal: seu fluxo incessante e sua presença constante. Wittgenstein certamente sofreu uma forte tentação, durante alguns meses do ano de 1929, de ver na descrição jamesiana uma representação adequada da temporalidade fenomenológica, embora para ele as propriedades apresentadas por James como factuais e empíricas deveriam obviamente ser consideradas como lógicas e a priori - enfim, «fenomenológico» não quer dizer «fenomenal». Alguns textos são extremamente claros acerca dessa proximidade com James:

Der entscheidende Moment für eine Sprache ist ihre Anwendung. Das Denken mit ihrer Hilfe.

Die Betrachtungsweise die gleichsam in einen Talkessel hinunter führt aus dem kein Weg in die freie Landschaft führt ist die Betrachtung der Gegenwart als des einzig Realen. Diese Gegenwart in ständigem Fluss oder vielmehr in ständiger Veränderung begriffen lässt sich nicht fassen. Sie verschwindet ehe wir daran denken können sie zu erfassen [James cita o célebre verso de Boileau : «Le moment où je parle est déjà loin de moi ${ }^{3}$ ]. In diesem Kessel bleiben wir in einem Wirbel von Gedanken verzaubert stecken.

Der Fehler muss sein dass wir versuchen die fliehende Gegenwart mit der wissenschaftlichen Methode zu erfassen (Item 107, p. 2, grifo nosso). ${ }^{4}$

A imagem jamesiana é aqui empregada de modo não crítico; dito de outro modo: Wittgenstein interroga-se acerca do modo correto de apreender die fliehende Gegenwart, sem se interrogar sobre a existência de tal coisa. Assim sendo, o problema com o qual ele se defronta é um problema metodológico; ele ainda não se pergunta se a própria imagem do presente fluente é legítima ou não. Outras reflexões derivam manifesta- 
mente da mesma origem. O uso recorrente que Wittgenstein faz da analogia cinematográfica ao longo do período intermediário é também seguramente o legado da concepção psicológica exposta por James. É aliás notável que o modo pelo qual Wittgenstein emprega de início essa analogia não põe em questão a aplicação do termo "presente» à imagem na tela, como Wittgenstein o fará mais tarde (nas Philosophische Bemerkungen, notadamente) ao rejeitar a idéia de que a experiência poderia ser qualificada de «presente» do ponto de vista fenomenológico - e a analogia será então utilizada de um modo diferente ${ }^{5}$. Como Wittgenstein o diz de forma bastante clara nessa época:

Wenn ich die Tatsachen des ersten Systems mit den Bildern auf der

Leinwand und die Tatsachen des zweiten Systems mit den Bildern auf dem Filmstreifen vergleiche so gibt es auf dem Filmstreifen ein gegenwärtiges Bild, vergangene und zukünftige Bilder; auf der Leinwand aber, ist nur die Gegenwart (item 105, p. 86).

Assim, do mesmo modo que podemos ver na tela o fluxo das imagens da película ao passo que a luz permanece projetada na tela, os fenômenos mudam incessantemente ao passo que a experiência ela própria permanece incessantemente presente. As afirmações mobilista e solipsistainstantaneísta, ao que me parece, provêm elas próprias da imagem do specious present: o mobilista é fascinado pelo aspecto fluente (Alles fliesst), se assim se pode dizer, e o solipsista instantaneísta pelo caráter permanente do presente fluente (Nur die gegenwärtige Erfahrung ist real). A esse respeito, é bastante notável que essas duas figuras filosóficas façam sua entrada na cena do pensamento wittgensteiniano ao mesmo tempo (cf. item 108, p. 1-2), como se elas constituíssem duas expressões da mesma imagem filosófica, a saber: a de James.

Não há, portanto, nada de surpreendente no fato de que os textos do ano de 1929 tragam um questionamento insistente sobre a estrutura lógica dessa temporalidade fenomenológica ${ }^{6}$, antes que Wittgenstein venha a tomar consciência do caráter filosoficamente errôneo dessas afirmações. Mas a adoção provisória da imagem do specious present leva a outra conseqüência, mais problemática. Sabe-se perfeitamente que a linguagem «primária» ou «fenomenológica» tem por tarefa descrever a sucessão dos fenômenos com o objetivo de revelar suas formas lógicas - eis o que se 
espera que venha a ser oferecido pela investigação a posteriori dos fenômenos de que fala Wittgenstein em seu artigo de 1929 (WITTGENSTEIN, 1993) - e sabe-se também que essa função da linguagem primária não é ali claramente distinguida da mera elucidação do sentido de nossos conceitos fenomenológicos. Os modelos dinâmicos (as máquinas de descrever) cuja construção ele imagina nessa época ${ }^{7}$ são todas elas tentativas de fabricar a nova notação «fenomenológica» que ele então procura com o objetivo de apreender (entre outras coisas) os traços lógicos temporais dos fenômenos. Mas, é claro, dado o modo pelo qual o objeto a ser descrito é concebido, vê-se mal como se poderia conseguir descrevê-lo. Está absolutamente fora de questão que uma linguagem possa ser estritamente simultânea a uma simples gota temporal sem ser imediatamente reduzida a um «unartikulierter Laute» (item 105, p. 110/WITTGENSTEIN, 1984, \$ 68). Compreende-se então que uma razão importante para o abandono do projeto de uma linguagem fenomenológica resida na imagem da temporalidade dos fenômenos que Wittgenstein adotava em 1929. A observação seguinte é perfeitamente clara a esse respeito, graças ao recurso à analogia cinematográfica:

Die Annahme dass eine phänomenologische Sprache möglich wäre und die eigentlich erst das sagen würde was wir in der Philosophie ausdrücken wollen, ist - glaube ich - absurd. (...)

Ich meine: was ich Zeichen nenne muss das sein was man in der Grammatik

Zeichen nennt, etwas auf dem Film nicht auf der Leinwand (Item 107, p.

176 - grifo nosso).

Portanto, Wittgenstein pensava, em outubro de 1929, que a forma fenomenológica da temporalidade era tal que era impossível enunciá-la. Desse ponto de vista, a impossibilidade da linguagem fenomenológica se impõe como factual: por causa do caráter fluente do presente, uma sua descrição verbal não poderia ser simultânea (uma vez que uma proposição toma tempo), ao passo que essa simultaneidade é um dos requisitos que pesam sobre a linguagem fenomenológica. Mas Wittgenstein irá logo modificar seu diagnóstico e pensar, a partir de então, que a verdadeira dificuldade não é conseqüência da suposta incompatibilidade entre o fluxo dos fenômenos e a inevitável extensão temporal de toda proposição descritiva. 
2. De fato, para o Wittgenstein de 1930 (e, portanto, para o das Philosophische Bemerkungen), o fluxo fenomenal e a estreita ilhota do presente em seu seio são meras ilusões produzidas pela confusão entre certas propriedades lógicas de nossa linguagem e propriedades factuais. Uma observação de dezembro de 1929 é explícita a esse respeito:

Was zum Wesen der Welt gehört, kann die Sprache nicht ausdrücken.

Daher kann sie nicht sagen, dass alles fliesst. Nur was wir uns auch anders vorstellen könnten, kann die Sprache sagen.

Dass alles fliesst, muss in der Anwendung der Sprache ausgedrückt sein, und zwar nicht in einer Anwendungsart, im Gegensatz zu einer andern, sondern in der Anwendung. In dem, was überhaupt die Anwendung der Sprache nennen.

Unter Anwendung verstehe ich das, was die Lautverbindungen oder Striche überhaupt zu einer Sprache macht. In dem Sinn, in dem es die Anwendung ist, die den Stab mit Strichen zu einem Masstab macht.

Das Anlegen der Sprache an die Wirklichkeit.

Und dieses Anlegen der Sprache ist die Verifikation der Sprache (Item 108, p. 1/Item 209, p. 30 -WITTGENSTEIN, 1984, \$54). ${ }^{8}$

Leio esse texto como uma crítica - formulada no estilo do Tractatus da fenomenologia do Tempo de 1929, como se Wittgenstein quisesse, ao recorrer ao dictum de Heráclito, Alles fliesst, capturar uma imagem (Bild) sob o domínio da qual ele se encontrava algumas semanas antes. De fato, sabe-se perfeitamente que Wittgenstein adere a certo verificacionismo por volta de 1930, como o mostra a citação precedente: a aplicação da linguagem à realidade é a verificação da linguagem, e a significação de nossas palavras consiste em seu método de verificação. Além disso, Wittgenstein distingue, nessa mesma época, dois tipos de enunciados: de um lado a «hipótese», de outro a «proposição fenomenológica». No contexto verificacionista então vigente, essa distinção equivale a uma distinção entre dois modos pelos quais proposições podem ser verificadas pela realidade: mais exatamente, ao passo que as proposições autênticas podem ser «verificadas» no sentido estrito, as hipóteses podem ser "confirmadas», confirmação essa que repousa sobre a verdade das primeiras (cf. WITTGENSTEIN, 1984, cap. XXII). 
Creio que o abandono da imagem do presente fluente está vinculado a essa concepção. De fato, como vimos, um ponto essencial para Wittgenstein consiste em que as afirmações mobilista e solipsista-instantaneísta são equivocadas porque procuram dizer o que só pode ser mostrado; por isso, elas confundem traços lógicos de nossa linguagem com propriedades factuais : elas confundem ambas «die Möglichkeit derVeränderung», i.e., o tempo em seu estatuto lógico, com uma mudança factual (item 108, p. 32-3/WITTGENSTEIN, 1984, \52). Conseqüentemente, o mobilista e o solipsista se representam os modos de verificação (no sentido amplo) próprios das hipóteses e das proposições fenomenológicas sob a forma, respectivamente, de um fluxo e de uma fatia de presente recortada no interior desse fluxo: uma vez que as hipóteses são confirmadas por experiências sucessivas e uma vez que cada proposição fenomenológica é verificada pela experiência presente que ela descreve, o mobilista e o solipsista traduzem a temporalidade inerente à gramática de nossos enunciados (i.e., os modos pelos quais são verificados) na mitologia de uma superrealidade e acreditam, desde então, que a forma fenomeno-lógica temporal da realidade é um fluxo constante centrado no presente. É justamente o que sustentaria um advogado da concepção do specious present, qualquer que seja a versão escolhida, quer se trate da versão psicológica de James, da versão metafísica de Bergson ou da versão fenomenológica de Husserl. Como diz Wittgenstein:

Der Strom des Lebens, oder der Strom der Welt [e, como se sabe, „die

Welt" não é nada além do conjunto dos fenômenos para o

Wittgenstein dessa época - cf. WITTGENSTEIN, 1984, \225g], fliesst dahin [,alles fliesst"], und unsere Sätze werden, sozusagen, nur in

Augenblicken verifiziert.

Unsere Sätze werden nur von der Gegenwart verifiziert (item 107, p. 222/item 209, p. 18 - WITTGENSTEIN, 1984, \48).

Estou fortemente inclinado a acreditar que, nas Philosophische Bemerkungen, Wittgenstein não aceita nem o que é afirmado por esse texto nem o que é afirmado pelas observações que o seguem imediatamente - penso na pretensamente necessária «Kommensurabilität mit der Gegenwart». Parece-me que a seção 54 desenvolve antes uma crítica desse tipo de afirmação, como se Wittgenstein começasse por formular sua própria 
tentação na seção 48 antes de procurar mostrar porque ela é desprovida de sentido - e, de modo mais geral, pode-se ressaltar o fato de que as Philosophische Bemerkungen desdobram assim um primeiro nível crítico da fenomenologia de $1929^{9}$. Desse modo, a idéia de que Alles fliesst e de que nossas proposições deveriam possuir determinada feitura a fim de poderem ser verificadas encontra sua fonte na confusão cometida acerca de nossa linguagem, como o diz, aliás claramente, o início da seção 49. Em outros termos, ao passo que em 1929 Wittgenstein apresenta uma teoria que está muito próxima da aceitação de uma descrição a posteriori das formas fenomeno-lógicas, ele a despede nas Philosophische Bemerkungen por meio de uma posição do Tractatus, muito próxima daquela expressa pela observação 3.362: "Was in den Zeichen nicht zum Ausdruck kommt, das zeigt ihre Anwendung. Was die Zeichen verschlucken, das spricht ihre Anwendung aus». O que, em 1929, significa que os modos pelos quais nossas proposições são verificadas são «mostrados» por seu uso; mas, uma vez que se trata de um traço lógico, não tem nenhum sentido procurar «dizê-los». Portanto, não há nenhum fluxo que infelizmente não conseguiríamos dizer - ou então as observações de Wittgenstein seriam grosseiramente contraditórias -, e a própria imagem do fluxo dos fenômenos e do specious present é uma simples ilusão. Pode-se então dizer, para concluir esse ponto, que as Philosophische Bemerkungen encerram o episódio fenomenológico relativo ao tempo: Wittgenstein já não crê na idéia de um presente absolutamente fluente, ainda que ele continue pensando que se trata de uma imagem filosófica muito importante e que merece um exame cuidadoso.

3. Wittgenstein efetua um passo suplementar por volta de 1931-1932trata-se daquilo que W. Kienzler chama «die Wiederaufnahme» (KIENZLER, 1997) -, pois doravante ele considera que a própria razão (o «motivo», como diz P. Hacker - HACKER, 2000, p. 365) que o conduziu precedentemente a formular e rejeitar a afirmação mobilista e solipsista instantaneísta é ilusória. Não há, com efeito, de modo algum algo de essencial, algo cuja apreensão nos condenaria aos contra-sensos mobilista e solipsista; sua origem está alhures. Tal é o nervo da retomada que Wittgenstein efetua, dois anos mais tarde, com relação às observações supracitada:

[As três primeiras frases voltam sem alterações] Dass alles fliesst, muss im Wesen der Berührung der Sprache mit der Wirklichkeit liegen. 
Oder besser: dass alles fliesst muss im Wesen der Sprache liegen.

Und, erinnern wir uns: im gewöhnlichen Leben fällt uns das nicht auf

- wie wenig wie die verschwommenen Ränder unseres Gesichtsfelds

(,weil wir daran gewöhnt sind“ wird mancher sagen). Wie, bei welcher

Gelegenheit, glauben wir denn darauf aufmerksam zu werden? Ist es

nicht, wenn wir Sätze gegen die Grammatik der Zeit bilden wollen?

(item 114, p. 21)

A principal modificação consiste aqui numa certa separação entre a idéia do fluxo e toda temporalidade lógica (ou gramatical) : a imagem do fluxo não é uma vã tentativa que visa dizer uma temporalidade lógica que só pode ser mostrada pela aplicação de nossa linguagem; antes, é a própria idéia de uma essencial temporalidade do mundo que é um contra-senso. Doravante, a imagem do presente fluente depende exclusivamente do que é nossa linguagem (de sua «essência»), i.e., de nossa "gramática do tempo» e dos mal-entendidos que ela é capaz de suscitar. Por conseguinte, a questão já não é a de saber que propriedades essenciais da linguagem e do mundo levam o filósofo ao contra-senso, mas que traços de nossa linguagem podem produzir a sensação de que haveria algo de essencial que poderíamos fracassar em dizer.

Wittgenstein considera, por fim (por volta de 1932-1933), que o modo pelo qual ele anteriormente concebeu a temporalidade fenomenológica e sua importância (a despeito da ausência de sentido de suas pretensas descrições) resultava de uma das tendências mais falaciosas do espírito humano: a saber, a crença de que o todo da realidade está contido no presente, ou ainda, a tendência à "presentificação", segundo a qual a vida psicológica e a atividade semântica, especialmente, seriam exclusivamente presentes - podemos nos ver tentados a dizer, por exemplo:

Es ist eine merkwürdige Tatsache, dass ich mich beim Gebrauch der Sprache nicht erinnere, wie ich sie gelernt habe. Ich sage „hier sehe ich eine schwarze Kugel“. Ich weiss nicht, wie ich „schwarz“ und „Kugel“" gelernt habe. Meine Anwendung der Wörter ist unabhängig von diesem Erlernen. Es ist so, als hätte ich diese Wörter selbst geprägt (item $213, \mathbb{S} 37$, p. 150 - grifo nosso).

Eis o que Wittgenstein chama alhures «pôr o presente sobre um pedestal» ou «coroá-lo» (WITTGENSTEIN, 1993b, p. 337). Como procurarei 
mostrar, um dos fios condutores do pensamento de Wittgenstein após 1929 não é senão o processo pelo qual o olhar que ele endereça à gramática da memória se liberta desse «mito do presente» - esclareço que minha segunda seção irá se debruçar na lembrança episódica na medida em que é um dos principais exemplos considerados por Wittgenstein, e que eu qualifico de "episódica» a lembrança que versa sobre alguma coisa que eu percebi ou um acontecimento que presenciei ${ }^{10}$.

\section{A lembrança: das relações externas às relações internas}

1. O problema empirista da lembrança: a intencionalidade temporal e o papel da verificação da lembrança

1. Os resultados precedentes irão me ajudar a clarificar o que Wittgenstein poderia estar pensando acerca da lembrança nas cercanias de 1930: eles certamente constituem um pano de fundo sobre o qual se pode compreender a filosofia da psicologia de Wittgenstein; e não apenas aquela do início dos anos 30 (como irei mostrar), mas também aquela dos anos 40 (acerca da qual não falarei aqui) - é que o mito do presente bloqueia uma visão correta do uso efetivo de nossos termos psicológicos.

Wittgenstein formula em 1929 dois problemas conexos acerca da lembrança : um versa sobre a intencionalidade da lembrança, e o outro sobre o papel desta última na verificação. De modo relativamente evidente, esses dois problemas encontram sua origem na Analysis of Mind de Russell, ou seja, no modo empirista de conceber a lembrança, que também encontramos nos Principles of Psychology de James. Russell, de fato, põe duas questões, que Wittgenstein retomará por conta própria:

In regard to memory, as throughout the analysis of knowledge, there are two very distinct problems, namely:

(1) as to the nature of the present occurrence in knowing;

(2) as to the relation of this occurrence to what is known.

When we remember, the knowing is now, while what is known is in the past. Our two questions are, in the case of memory

(1) What is the present occurrence when we remember? 
(2) What is the relation of this present occurrence to the past event which is remembered?

Of these two questions, only the first concerns the psychologist; the second concerns theory of knowledge (RUSSELL, 1997. Lecture IX, p. 173).

Em outras palavras, o problema empirista da memória comporta dois aspectos ao mesmo tempo cruciais e perfeitamente clássicos: (1) como algo presente pode manter uma relação com algo passado? Como se sabe, um dos traços principais da temporalidade fenomenológica reside no fato de que «tudo que é fenomenal é presente» (como diz Wittgenstein, «in der Welt der Data (...) ich habe eben gegenwärtige Sinnesbilder und gegenwärtige Erinnerungsbilder» - Item 105, p. 86). Portanto, que marca ou que sinal no material psicológico presente da lembrança constitui a diferença que separa uma imagem relativa ao passado de uma imagem relativa ao futuro? Como compreender a «Beziehung auf dieVergangenheit» própria da «Erinnerungsbild»? Encontramos aqui o problema da intencionalidade temporal da lembrança. Como diz Wittgenstein :

Man kann natürlich sagen: ich sehe nicht die Vergangenheit sondern nur ein Bild der Vergangenheit. Aber woher weiss ich dass es ein Bild der Vergangenheit ist, wenn dies nicht im Wesen des Erinnerungsbildes liegt? (item 105, p. 96/WITTGENSTEIN, 1984, \50/item 213, 105, p. 520)

O segundo problema é um corolário do precedente: (2) em que medida a lembrança é capaz de desempenhar um papel epistêmico? De modo mais preciso, estaria ela em condições de verificar uma proposição relativa ao passado? Isto é: mantém ela uma relação tal com os acontecimentos passados que possa decidir o valor de verdade de uma proposição no passado? Como se vê, os dois problemas da intencionalidade da lembrança e do conhecimento mnemônico estão ligados entre si.

Wittgenstein pensa no segundo desses problemas quando ele escreve, de modo crítico, acerca da analogia da lembrança com uma imagem:

Es muss zu Unsinn führen, wenn man mit der Sprache dieses

Gleichnisses über das Gedächtnis als Quelle unserer Erkenntnis, als 
Verifikation unserer Sätze, reden will (item 108, p.

34/WITTGENSTEIN, 1984, \$ 49).

2. Ainda que ela se estabeleça num nível lógico e não psicológico, a primeira solução que Wittgenstein traz para esses problemas permanece profundamente inscrita no contexto oferecido pelo empirismo, já que continua a recorrer à imagem do specious present. Essa solução nos permite responder as questões espinhosas que eu mencionei graças a uma explicação genética do «feeling of pastness» : uma vez que o presente fenomenológico é dotado de uma certa duração, exatamente como o specious present, a consciência do estrito presente é sempre mesclada à daquilo que era estritamente presente um instante antes e que doravante é recémpassado; a consciência desse feeling recém-passado (trata-se da «memória primária» dos empiristas) constitui a experiência fundamental do passado; por sua associação com uma imagem na mente, ela haveria de conferir a essa imagem sua intencionalidade temporal. Cabe realmente reconhecer que Wittgenstein, no mínimo, flerta com essa concepção em 1929, sem abordá-la de modo crítico:

Wenn man fragt: "Welches Erlebnis liegt dem Zeitbegriff, der Annahme einer Zeit, zugrunde?" Wie muss man antworten? - Es ist die

Erinnerung, wenn es eine punktartige Gegenwart gibt; oder es ist eine kontinuierliche Wahrnehmung deren einer Endpunkt die Gegenwart ist und die im weiteren Sinne auch Erinnerung nennen kann (item 105, p. 98 - grifo nosso).

Essa última formulação coincide bastante bem, ao que me parece, com aquilo que James e Russell disseram acerca da «lembrança primária».

2. A confusão entre o lógico e o factual. Suas conseqüências para o problema da lembrança

No início dos anos 1930, no entanto, Wittgenstein adota uma posição nitidamente diferente e certamente muito mais interessante que a da primeira solução trazida para o problema da intencionalidade da lembrança. 
1. Primeiro, ele considera que certos erros filosóficos relativos à lembrança estão estreitamente ligados à concepção mobilista. Ele distingue, com efeito, dois modos de empregar a palavra "memória» : de um lado, «als aufbewahrtes Bild des vergangenen Ereignisses», a memória é apenas um meio entre outros de guardar o vestígio ou o testemunho dos acontecimentos passados; de outro, "als Quelle der Zeit», ela define a própria ordem temporal - e, correspondentemente, «tempo» pode ter dois sentidos diferentes, a saber, o sentido fisicalista e fenomenológico. $\mathrm{Na}$ seção 49 das Philosophische Bemerkungen (cf. tb. item 108, p. 33), Wittgenstein toma como alvo um determinado modo de confundir esses dois sentidos: o que consiste em atribuir à forma lógica do tempo fenomenológico certas propriedades factuais que pertencem aos acontecimentos físicos; i.e., atribui-se à ordem temporal da memória o traço de sucessividade dos acontecimentos físicos, como se se acreditasse que o fato do desenrolar da película fosse uma propriedade essencial (lógica) da imagem na tela; por conseguinte, confunde-se «o que está em um espaço» - a saber, o desdobramento no espaço físico - com «o que é um espaço» - a saber, o espaço fenomenal definido pela memória «als Quelle der Zeit» (cf. WITTGENSTEIN, 1984, \$ 54/item 108, p. 3) :

«Wir stellen uns das Erleben wie einen Filmstreifen vor, so dass man sagen kann: dieses Bild, und kein anderes, ist in diesem Augenblick vor der Linse» (Item 111, p. 8/item 213, 102, p. 495).

Essa Übertragung produz ao mesmo tempo tanto a sensação de que «das Phänomen uns entschlüpft» quanto a idéia do «ständigen Fluss der Erscheinung», expressa pela afirmação mobilista, como se o fluxo fosse a forma lógica dos fenômenos - essa confusão é uma das numerosas genealogias do dictum Alles fliesst que Wittgenstein propõe no início dos anos 30. A conseqüência disso é que se dirá da lembrança que ela é uma representação dos fatos essencialmente deficiente:

Dabei kommt es vor, als wäre die Erinnerung eine etwas sekundäre Art der Erfahrung, im Vergleich zur Erfahrung des Gegenwärtigen. Wir sagen, ,daran können wir uns nur erinnern“. Als wäre in einem primären Sinn die Erinnerung ein etwas schwaches und unsicheres 
Bild dessen, was wir ursprünglich in voller Deutlichkeit vor uns hatten (item 108, p. 27/WITTGENSTEIN, 1984, \52).

Segundo essa concepção, de fato, a memória seria formada por imagens (Bilder). Mas adotar tal diagnóstico equivale a sustentar que é sempre externa a relação que vincula uma lembrança ao que por ela é rememorado, como toda relação entre dois acontecimentos físicos: «lembrança» não seria nunca utilizado como uma definição da ordem temporal e não seria nunca mais do que um simples «Symptom» do passado (item 213, \ 102, p. 495). Torna-se, desde então, impossível compreender como a memória poderia assegurar a verificação de nossas proposições no passado, a menos que se conceda que ela só pode fornecer uma verificação imperfeita. É precisamente o que lançava Russell na perplexidade:

Why do we believe that images are, sometimes or always, approximately or exactly, copies of sensation? What sort of evidence is there? And what sort of evidence is logically possible? The difficulty of this question arises through the fact that the sensation which an image is supposed to copy is in the past when the image exists, and can therefore only be known by memory, while, on the other hand, memory of past sensation seems only possible by means of present images. How, then, are we to find any way of comparing the present image and the past sensation? (...) it is the very possibility of comparing that is hard to understand (RUSSELL, 1997, p. 158-9).

A bem dizer, o verdadeiro problema é que a significação atribuída à «memória» está longe de esgotar o uso que fazemos dessa palavra. Mas, enquanto permanecemos sob a fascinação do uso exclusivamente fisicalista (i.e., a lembrança como imagem presente), encontramo-nos impossibilitados de ver o uso de "memória» «als Quelle der Zeit». Seguramente, Wittgenstein ainda recorre, em 1930, a uma distinção excessivamente rígida e dogmática entre os planos físico e fenomenológica - ele fala ainda da diferença «der Zeitbegriff im ersten System von dem in der Physik» (item 209, \$50), herdada do período fenomenológico. Assim, nas Philosophische Bemerkungen, ele afirma que só se pode falar de acontecimentos físicos no tempo físico, ao passo que parece bastante evidente que, como ele próprio dirá mais tarde, a 
memória como «fonte do tempo» contém freqüentemente acontecimentos físicos:

Gedächtniszeit. Sie ist (wie der Gesichtsraum) nicht ein Teil der grossen

Zeit, sondern die spezifische Ordnung der Ereignisse oder Situation im

Gedächtnis // in der Erinnerung (item 213, \$ 105, p. 521 - grifo nosso).

Essa observação, que se encontra na seção 105 do Big Typescript (item 213), nos permite compreender qual o sentido da retomada, por Wittgenstein, das observações que ele consagra ao Gedächtniszeit nas Philosophische Bemerkungen, de modo paralelo à sua retomada das observações que versam sobre o mobilismo. Notar-se-á, de início, que ele substitui, nessa seção, o termo Zeitraum pelo de Ordnung (cf. item 213, p. 517, 520, 521) que ele usava em 1930 para referir-se à experiência imediata (cf. WITTGENSTEIN, 1984 \54f). A razão disso certamente consiste no fato de que ele deseja afastar a tentação de considerar o tempo como algo existente por si mesmo, do mesmo modo que podemos nos ver tentados a considerar o espaço visual como um objeto (cf. item $213, \mathbb{\$} 97$ ): seria absurdo, por exemplo, acreditar que «existe» algo como a forma lógica temporal dos fenômenos, que seríamos incapazes de enunciar, como acreditava Wittgenstein em 1930. A noção de ordem, pelo contrário, designa simplesmente um modo de combinar certos elementos, sem sugerir a existência de uma forma misteriosa, e, por conseguinte, ela remete exclusivamente à questão dos critérios do uso. Dito de outra forma, Wittgenstein doravante afirma simplesmente que há diferentes critérios para pôr em ordem as coisas e os acontecimentos no tempo, e que a memória é um desses critérios (é nesse sentido que ela é «ein bestimmter Teil der logischen Struktur unserer Welt» - item 213, \102, p. 495). Por exemplo, imaginem que alguém procure se lembrar como outra pessoa estava vestida alguns dias antes, i.e., se lembrar de um acontecimento físico; ele pensará então em diferentes roupas possíveis até chegar à roupa correta; nesse caso, é a memória que desempenha o papel de critério daquilo que era o acontecimento físico. Esse uso corriqueiro de «memória» não abre espaço para uma dúvida relativa à afirmação mnemônica de que o Sr. N. estava vestido de tal e tal maneira alguns dias atrás; por conseguinte, não cabe perguntar como a lembrança e aquilo que é lembrado poderiam ser «comparados», uma vez que aquilo com 
que a lembrança deveria ser comparada é definido pela própria lembrança - como o diz Wittgenstein: «o critério do acordo [entre o acontecimento passado e tal ou tal representação do modo pelo qual o Sr. N. estava vestido ontem] é aqui a lembrança» (WITTGENSTEIN, 1997, p. 151). Wittgenstein necessitava dessa evolução para poder deixar de falar dos dois «sistemas» como dois níveis heterogêneos da linguagem, e para ver claramente a função desempenhada por nosso conceito de lembrança. Não obstante, por rígida que fosse, a formulação de 1930 já dizia que a concepção da "comparação» defendida por Russell acerca da lembrança é equivocada por pressupor um conceito unívoco de lembrança.

Mas voltemos ao ano de 1930. A concepção mobilista não é a única que mergulha a filosofia da lembrança na perplexidade; o solipsismo instantaneísta também tem o mesmo efeito. Acabamos de nos defrontar, uma vez mais, com o mito do presente. Restringir o uso de «lembrar» à sua sintaxe física leva, de fato, não apenas à idéia de que os fenômenos fluem constantemente em direção do passado, mas igualmente à impressão de que o presente se basta a si mesmo, uma vez que ele não mantém nenhuma relação necessária com o passado. É o que sugere a famosa hipótese russelliana, segundo a qual:

There is no logical impossibility in the hypothesis that the world sprang into being five minutes ago, exactly as it then was, with a population that "remembered" a wholly unreal past (RUSSELL, 1997, p. 159).

Para Wittgenstein, essa autarcia do presente é na verdade ilusória, uma vez que os fenômenos não podem ser qualificados como «presentes»:

Wenn man sagt, die gegenwärtige Erfahrung nur hat Realität, so muss hier schon das Wort ,gegenwärtig“ überflüssig sein (...). Denn es kann nicht heissen gegenwärtig im Gegensatz zu vergangen und zukünftig (WITTGENSTEIN, 1984, \54).

Em outras palavras, a sensação de que nós e todos os componentes de nossa vida psíquica estamos sempre no presente surge assim que aplicamos aos fenômenos o conceito fisicalista de presente:

Der Zeitmoment, von dem ich sage, er sei die Gegenwart, die alles enthält, was mir gegeben ist, gehört selbst zur physikalischen Zeit (item 111, p. 8/item 213, p. 494). 
A conseqüência disso é que tudo o que aparece no campo fenomenal parece estar presente, e, em particular, tanto a lembrança quanto aquilo que é lembrado. De onde a idéia jamesiana e russelliana de que a intencionalidade mnemônica repousa sobre o «feeling of pastness», que apresenta a imensa vantagem de ser algo presente.

2. Certamente, a réplica de Wittgenstein impugna, já em 1930, a própria posição do problema que suscita a concepção empirista; a arma que ela emprega para fazê-lo é a das relações internas - o que já ocorria, como vimos, com a distinção dos dois sentidos de «memória» nas Philosophische Bemerkungen. Isso significa, mais precisamente, que Wittgenstein irá libertar-se do mito do presente, tal como ele afeta a filosofia da psicologia, via a crítica desse mito em sua dimensão semântica: aquela requer esta. Parece-me, de fato, que, nas Philosophische Bemerkungen, Wittgenstein ainda adere a certa versão semântica desse mito, muito embora ele já o conteste em sua dimensão psicológica. Assim, um dos fios importantes no seio da evolução de Wittgenstein ao longo de seu período intermediário consiste na recusa dessa imagem semântica terrivelmente sedutora. Comecemos por dizê-lo numa palavra: cumpre reconhecer que uma proposição no passado é tão determinada do ponto de vista semântico quanto uma proposição no presente e, por conseguinte, que uma proposição de lembrança não é semanticamente inferior a uma proposição no presente, como tampouco uma lembrança é «eine etwas sekundäre Art der Erfahrung». Gostaria de tornar esse ponto mais preciso.

O mito semântico do presente repousa sobre o verificacionismo do Wittgenstein de 1930. Como vimos, as «hipóteses» são então distinguidas das «proposições» por seu método de verificação no sentido amplo. É bastante notável que na $5^{\mathrm{a}}$ parte das Philosophische Bemerkungen, quando ele expõe essa distinção em seu aspecto temporal, e logo após ter dito que a imagem do presente fluente é desprovida de sentido, Wittgenstein ainda adote, de modo bastante paradoxal, uma posição que é da ordem do mito do presente: com efeito, a fim de afastar a afirmação de que «nur die gegenwärtige Erfahrung ist real», ele diz que uma proposição no passado (i.e., uma hipótese) «hat auf eine indirektere Art Sinn, als» uma verdadeira proposição. Segundo ele, isso ocorre, por exemplo, no caso das duas frases «Cäsar zog über die Alpen» (que é uma hipótese) e «Ich sehe einen roten Fleck über einen grünen dahinziehen» (que é uma proposição) ${ }^{11}$. 
Pode-se notar que essa posição é coerente com o que Wittgenstein explica, na mesma época, acerca do tempo e da verificação: como eu disse, Wittgenstein pensa que a forma lógica temporal de nossa linguagem pode apenas ser mostrada por meio do modo pelo qual nossas proposições são verificadas, toda tentativa de enunciá-la sendo condenada ao contra-senso, como no caso das afirmações mobilista e solipsista; por conseguinte, o dictum solipsista instantaneísta será rejeitado ao se sustentar que o que esse dictum procura dizer só pode ser mostrado nos modos pelos quais nossas proposições têm sentido - i.e., nos modos pelos quais elas são verificadas. O ponto importante é que Wittgenstein evoca justamente esses diferentes modos pelos quais elas são verificadas à guisa de argumento quando ele distingue os estatutos semânticos respectivos da hipótese no passado e da proposição no presente - nesse sentido, o que nos liberta da imagem do presente fluente nos joga nos braços do mito semântico do presente.

Seguramente, assim que se diz que a significação de uma frase consiste em seu método de verificação, parece bastante evidente que o fato de ter um sentido, para uma frase no passado, é algo menos «direto» e menos «imediato» do que para uma frase no presente, em razão do abismo temporal que separa o passado do presente - Wittgenstein, aliás, não explica de modo algum o que convém entender por «direto» e «imediato». Assim sendo, se ele tivesse realmente rejeitado a posição de Russell que ele critica na seção 56, ele não teria criticado exclusivamente a diferença no seio da crença mnemônica entre o objective (i.e., o acontecimento passado ele próprio) e what is believed (i.e., aquilo que Wittgenstein chama o Mittelglied do conteúdo psicológico presente) ${ }^{12}$, mas também a idéia de que o abismo temporal confere um estatuto semântico inferior às proposições no passado: Wittgenstein de fato ainda pensa que uma proposição de lembrança fala do acontecimento passado ele próprio (pace Russell), mas de um modo semanticamente mais frouxo do que as proposições no presente acerca do próprio presente. Esse tipo de análise pressupõe que o vínculo semântico entre a frase presente e o fato passado ao qual ela se refere é inevitavelmente externo. Portanto, o verificacionismo de Wittgenstein no início dos anos 30 ratifica, por sua vez, um princípio superior, que tem sua origem no episódio fenomenológico, a saber: que o presente possui uma primazia semântica e que, conseqüen- 
temente, um fato preenche tanto melhor seu papel de referente quanto mais presente ele é.

3. Wittgenstein rompe profundamente com esse tipo de pressuposto por volta de 1932-1933, quando sua concepção semântica sofre uma mudança decisiva: ele deixa então de considerar os critérios de verdade como os únicos critérios suscetíveis de determinar a significação de nossas palavras. É interessante notar que essa mudança, que leva à concepção dos critérios que é característica das Investigações filosóficas, se realiza especialmente no tocante às proposições no passado, como o mostram claramente alguns cursos de Cambridge que datam dessa época.

Wittgenstein ali estabelece uma distinção interessante entre «being the meaning of» $\mathrm{e}$ "determining the meaning of»:

That I remember its raining yesterday helps determine the meaning of

"It rained yesterday", but it is not true that "It rained yesterday" means

"I remember that..."We can distinguish between primary and

secondary criteria of meaning. (...)

Reading that Cambridge won the boat race, which verifies

"Cambridge won", is obviously not the meaning, but it is connected with it (WITTGENSTEIN, 2001b, p. 28-9).

Tal análise nos põe diretamente diante do problema com o qual nos defrontávamos um pouco acima:

The verification of a proposition about the past is a set of propositions involving present and future tenses. If the verification gives the meaning, is part of the meaning left out [ou, nos termos do Wittgenstein de 1930: uma sentença no passado possui "seu sentido de um modo menos direto" do que a sentença no presente]? My reply is to deny that the verification gives the meaning. It only determines the meaning, i.e. determines its use, or grammar (ibid., p. 28-9). ${ }^{13}$

Seria fácil aplicar o que Wittgenstein diz aqui sobre as proposições no passado ao caso das proposições de lembrança: o fato de que uma imagem ou um sentimento esteja presente na mente de alguém no momento em que ele se lembra, ou então que percebamos a prova material de acontecimentos passados dos quais pretendemos nos lembrar, ou ainda que alguma outra pessoa confirme que efetivamente presenciamos o aconte- 


\section{8}

cimento do qual afirmamos nos lembrar, isso não dá a significação de «Eu me lembro»: esses fatos são "secondary criteria» ou «truth criteria» (ibid., p. 26) que podem verificar a afirmação "Eu me lembro», mas seria um equívoco dizer que "Eu me lembro de tal ou tal acontecimento» significa, por exemplo, «Uma outra pessoa confirma que eu efetivamente presenciei esse acontecimento». Além disso, se esses fatos dessem a significação, uma frase mnemônica versando sobre o passado seria na verdade uma frase relativa ao presente - Russell, aliás, se faz o paladino de um reducionismo temporal desse tipo na análise semântica que ele consagra à crença mnemônica, quando ele diz:

(...) everything constituting a memory-belief is happening now, not in that past time to which the belief is said to refer. It is not logically necessary to the existence of a memory-belief that the event remembered should have occurred, or even that the past should have existed at all (RUSSELL, 1997, p. 159).

Por conseguinte, na medida em que a verificação só é efetiva sob a condição de ser presente, o verificacionismo de Wittgenstein adota sempre a idéia de que a linguagem está centrada no presente, como se este fosse o único lugar em que a significação de nossas palavras pudesse ser determinada; desse ponto de vista, o passado, por exemplo, não poderia desempenhar nenhum papel semântico.

A ruptura introduzida no pensamento de Wittgenstein pela distinção entre as duas séries de critérios traz um elemento novo e decisivo para o tratamento wittgensteiniano dos critérios da lembrança. Doravante, possuir uma significação já não depende exclusivamente, para nossas palavras, daquilo que ocorre no presente. Como as citações precedentes o mostraram, graças ao abandono, por Wittgenstein, de todo verificacionismo dogmático, o papel semântico desempenhado pela relação com o passado já não pode ser «deixado de lado».

\section{O primado do interno e a rejeição do mito do presente}

Graças às análises que acabamos de evocar Wittgenstein está doravante em condições de reconhecer que a relação entre a proposição de 
lembrança e aquilo que é lembrado deve ser considerada como uma relação interna, e não (pace Russell) como uma relação factual: não é verdade que uma lembrança é uma lembrança independentemente do que quer que tenha ocorrido no passado, como se a existência do acontecimento passado do qual afirmamos nos lembrar não fosse «logicamente necessária» para que uma lembrança seja o que ela é. Assim, a novidade semântica dos «critérios primários» oferece a possibilidade de um novo modo de considerar a vida psíquica. De uma certa forma, ela realiza o programa esboçado nas seguintes linhas de 1931:

Es ist nämlich die Anschauung aufzugeben, dass, um vom

Unmittelbaren zu reden, wir von dem Zustand in einem Zeitmoment reden müssten. Diese Anschauung ist darin ausgedrückt, wenn man sagt: ,alles, was uns gegeben ist, ist das Gesichtsbild und die Daten der übrigen Sinne, sowie die Erinnerung, in dem gegenwärtigen

Augenblick“ (item 111, p. 5/item 213, \102, p. 494 - cf. tb. p. 495).

Em outras palavras, é um equívoco acreditar que a lembrança é «imediatamente dada», uma vez que o acontecimento passado desempenha um papel criterial essencial para a significação de «lembrar-se».

O episódio fenomenológico de 1929 deve portanto ser mais uma vez criticado, uma vez que ele faz da experiência, e especialmente da lembrança, algo que o presente determinaria inteiramente. No fundo, como o observa E. Anscombe, tal concepção redundaria em dizer que poderíamos forjar o verbo «to rember» a fim de designar um «memorydatum» supostamente formado pelo material puramente presente da lembrança, quer o acontecimento representado por esta seja real ou não. Mas: «"lembrar-se" não constitui um episódio que é o que ele é independentemente do fato de que algo de outro tenha sido o caso ou não» (ANSCOMBE, 1981, p. 124). Assim, para decidir se uma ocorrência mental presente versa ou não sobre o passado, é preciso analisar não o material psíquico presente, como se esperava que a linguagem fenomenológica fizesse, mas sim o suposto referente da ocorrência mental - o que exige levar em conta critérios que não são presentes: assim, caberá responder questões como «Você realmente presenciou o acontecimento do qual você pretende se lembrar ?». E, se respondermos sim: «é pelo fato de que você presenciou esse acontecimento que você se lembra dele?» 
Etc. O que ocorreu no passado determina portanto largamente a identidade daquilo que fazemos no presente; poder-se-ia ainda dizer que os acontecimentos passados desempenham o papel de "critérios primários» da lembrança, e também acrescentar que começarmos com o pretenso presente puro nos condena a permanecermos trancafiados nele; na investigação de nossa gramática do tempo, é preciso começar de imediato com o passado, o presente e o futuro. Portanto, ao fim e ao cabo Wittgenstein responde ao primeiro problema levantado por Russell dizendo que é o passado que decide se alguém se lembra ou faz algo diferente no presente; e ao segundo problema, dizendo que a lembrança é freqüentemente o critério de verificação da proposição de lembrança - temos aí um tipo de uso importante de nosso conceito de memória.

À guisa de conclusão, começarei por dizer que o combate entabulado por Wittgenstein contra o mito do presente no início dos anos 30 o liberta de uma imagem filosófica extremamente pregnante. Mesmo se os textos dos anos 40 não são sempre explícitos a esse respeito, a leitura dos textos do período intermediário mostra que as teorias da lembrança como vestígio, como sentimento, ou como imagem são criticadas nas observações sobre a filosofia da psicologia notadamente pelo fato de que repousam sobre o mito do presente. É o que afirma a seguinte observação:

Wenn ich sage "Vor einer halben Stunde war er da" - nämlich aus der

Erinnerung - so ist das nicht die Beschreibung eines gegenwärtigen

Erlebnisses.

Erinnerungserlebnisse sind Begleiterscheinungen des Erinnerns (PU, II, xiii, p. 579).

Para finalizar, direi que esse combate abre as portas para que se leve em consideração a dimensão temporal do contexto - dimensão cuja importância na segunda filosofia de Wittgenstein é bem conhecida. Sem dúvida, as considerações das Investigações filosóficas sobre o papel semântico desempenhado pela história ${ }^{14}$ encontram sua origem longínqua mas decisiva na rejeição do mito do presente. 


\section{Anexo}

Band I, Ms 108, p. 1 (13.12.29)

Ts 208, p. 111-112 (1930)

Ts 209 , p. 20 (1930)

Was zum Wesen der Welt gehört, kann die Sprache nicht ausdrücken. Daher kann sie nicht sagen, daß alles fließt. Nur was wir anders vorstellen könnten, kann die Sprache sagen.

$\mathrm{Daß}$ alles fließt, muß in der Anwendung der Sprache ausgedrückt sein, und zwar nicht in einer Anwendungsart, im Gegensatz zu einer andern, sondern in der Anwendung. In dem, was wir überhaupt die Anwendung der Sprache nennen.

Unter Anwendung verstehe ich das, was die Lautverbindungen oder Striche überhaupt zu einer Sprache macht. In dem Sinn, in dem es die Anwendung ist, die den Stab mit Strichen zu einem Maßtab macht. Das Anlegen der Sprache an die Wirklichkeit.

[Und dieses Anlegen der Sprache ist die Verifikation der Sprache. (Ms 108)]
Band X, Ms 114, p. 21r-v (03.06.32)

Ts 211, p. 763 (verão 1932)

Ts 213, \ 91 , p. 427 (1933)

Was zum Wesen der Welt gehört, kann die Sprache nicht ausdrücken. Daher kann sie nicht sagen, daß alles fließt. Nur was wir anders vorstellen könnten, kann die Sprache sagen.

[?- Daß alles fließt, muß in dem Wesen // im Wesen // der Anwendung der Sprache auf die Wirklichkeit liegen.? - (Ms 114 / Ts 211)]

// Daß alles fließt, muß im Wesen der Berührung der Sprache mit der Wirklichkeit liegen.// Oder besser: daß Alles fließt, muß im Wesen der Sprache liegen. Und, erinnern wir uns: im gewöhnlichen Leben fällt uns das nicht auf - sowenig, wie die verschwommenen Ränder unseres Gesichtsfelds (,weil wir so daran gewöhnt sind“", wird mancher sagen). Wie, bei welcher Gelegenheit, glauben wir denn, darauf aufmerksam zu werden? Ist es nicht, wenn wir Sätze gegen die Grammatik der Zeit bilden wollen? 
1 Item 105 (do catálogo de V. Wright), p. 11. As citações dos manuscritos e datiloscritos seguirão a codificação de V. Wrigth.

${ }^{2}$ Ver, de um lado, sec. 261 e 436, e, de outro, vol. 1 sec. 721.

3 Ibid., p. 573.

${ }^{4}$ Ver também o desenho na p. 159, assim como item 105, p. 98 e 114, onde encontramos uma alusão explícita ao specious present.

${ }^{5}$ Ver também item 213, \$ 105 , p. 519.

${ }^{6}$ Ver, por ex., item 105 , p. $84,86,88$

${ }^{7}$ Ver item 105, p. 108 e seg. / WITTGENSTEIN, 1984, \$ 67

8 O leitor encontrará, no final de meu texto, uma apresentação detalhada das diferentes etapas da formulação dessa observação ao longo do período intermediário.

${ }^{9}$ Esse não é o único exemplo nas Philosophische Bemerkungen: que se pense, por exemplo, nas máquinas de descrever na seção 67 , ou no estatuto do specious present na seção 69. Essa primeira etapa emprega as ferramentas fornecidas pelo Tractatus, i.e., antes de tudo a distinção entre o lógico e o factual, tal como ela é fixada pela distinção «dizer» / «mostrar». Desse modo, na seção 67, Wittgenstein nos previne contra o que é dito no item 105, p. 114 acerca do specious present, graças ao acréscimo dessa indicação crítica retomada do item 107, p. 176 (23.10.29, i.e., escrito após o abandono do projeto de uma linguagem fenomenológica): “Ich kann nicht wissen ob...' hat nur dann Sinn, wenn ich wissen kann; nicht, wenn es undenkbar ist". De fato, uma vez que a forma lógica temporal dos fenômenos não pode ser enunciada, não tem sentido dizer, por exemplo, de um lado, que eu não posso dizer que «Alles fliesst» ou que «Nur die gegenwärtige Erfahrung ist real», ao mesmo tempo em que se afirma que o presente fenomenológico é de fato algo como o specious present. Por conseguinte, os dicta mobilista e solipsista instantaneísta são puros contra-sensos. A Wiederaufnahme de que W. Kienzler fala constitui certamente uma segunda etapa crítica.

${ }^{10}$ Veja-se, por ex., CAMPBELL, 2001 e DOKIC, 2001.

11 WITTGENSTEIN, 1984, \$56/item 108, p. 7. Wittgenstein diz in unmittelbarerer Art no item 213, \ 103, p. 502.

${ }^{12}$ Ver RUSSELL, 1997, p. 233-234.

${ }^{13}$ Ver também PU, $\$ 353$.

14 Cf. $\$ 638,644,663$.

\section{Referências bibliográficas}

ANSCOMBE, G. E. 1981. "Memory, Experience and Causation", in Metaphysics and the Philosophy of Mind.The Collected Papers of G.E. Anscombe, vol. 2, Oxford: Blackwell. 
CAMPBELL, J. 2001. "Memory Demonstratives" in C. Hoerl and T. McCormack (ed.), Time and Memory. Oxford: Oxford University Press. DOKIC, J. 2001. “Is Memory Purely Preservative?” in C. Hoerl and T. McCormack (ed.), Time and Memory. Oxford: Oxford University Press. HACKER, P. 2000. "Was he trying to whistle it?" in A. Crary ed., The New Wittgenstein. London: Routledge.

HINTIKKA, J. 1996. Ludwig Wittgenstein: Half-Truths and One-and-aHalf-Truths. Dordrecht: Kluwer Academic Publishers.

JAMES, W. 1983. The Principles of Psychology (1890). London: Harvard University Press.

KIENZLER, W. 1997. Wittgensteins Wende zu seiner Spätphilosophie. Frankfurt am Main: Suhrkamp.

PARK, B.-C. 1998. Phenomenological Aspects of Wittgenstein's Philosophy. Dordrecht: Kluwer Academic Publishers.

RUSSEL, B. 1997. The Analysis of Mind. London: Routledge.

WITTGENSTEIN, L. 1984. Philosophische Bemerkungen. Werkausgabe Band 2, Frankfurt am Main: Suhrkamp. , 1993a. "Some Remarks on Logical Form". In: Ludwig Wittgenstein. Philosophical Occasions 1912-1951.Ed. James C. Klagge and Alfred Nordmann. Indianapolis and Cambridge, MA: Hackett, p. 28-35. ,1993b. "The Language of Private Experience and Sense Data”. In Philosophical occasions 1912-1951 p. 190/367 Indianapolis \& Cambridge: Hackett.

, 1994. Remarques sur la philosophie de la psychologie, tr. G. Granel, 2 vols., Mauvezin:T.E.R. , 1997. Dictées de Wittgenstein à Waismann et pour Schlick, Soulez, A. ed., Paris: P.U.F. ,2001a. Philosophical Investigations / Philosophische Untersuchungen, ed. G.E.M. Anscombe and R. Rhees, tr. G.E.M. 
Anscombe. Terceira edição (com tradução para o inglês revista). Oxford: Basil Blackwell

_ 2001b. "Philosophy 1932-1933”, in Wittgenstein's Lectures in Cambridge 32-35, New York: Prometheus Books. , 2005. The Big Typescript:TS 213. Eds. Luckhardt \& Aue.

Oxford: Blackwell. 